\title{
CULTUROLOGY
}

\section{LEISURE ACTIVITY AND ITS ROLE IN THE FORMATION OF CULTURE AND ETHICS OF THE INDIVIDUAL}

\author{
T. Salikaeva ${ }^{1}$ \\ DOI: http://doi.org/10.15350/L_26/8/01
}

\begin{abstract}
The article is devoted to leisure activities and its role in the formation of culture and ethics of the individual. Theoretical study of this phenomenon is of particular importance to improve the mechanisms of interaction leisure environment and personality by means of filling leisure time meaningful component that includes cultural and ethical aspects.
\end{abstract}

Keywords: leisure, leisure activities, culture, ethics, personality.

Современное общество, вступившее в эпоху глобализации, нуждается в осмыслении влияния досуговой деятельности на формирование личности. Сверхзадача данного аспекта - суметь привить личности правильные культурные и этические ценности, ведь на современном этапе можно выявить тенденцию «упрощение» досуга. Под этим понимается реализация досуговой деятельности посредством физической рекреации и развлечений, а не через рост духового содержания личности и развития внутреннего мира.

Для правильного понимания роли досуговой деятельности в процессе формирования личности необходимо правильно понимать термин «досуг».

В современной литературе досуговая деятельность не представлена как целостный объект анализа. Само же понятие «досуг» наиболее часто употребляется как нерабочая деятельность, свободное время, игра, удовольствие, развлечение, отдых и т.д. [2. с. 145].

В теории и практике термин «досуг» чаще всего трактуется как: свободное время (его часть);

нерабочая (свободная) деятельность с различными изменениями;

Досуговая деятельность подразумевает под собой свободный выбор личностью тот формат времяпрепровождения, который является для него наиболее приемлемым в силу индивидуальных предпочтений. Но нельзя забывать, что досуг подразумевает под собой выбор именно досуговых занятий.

1Tatiana Salikaeva, student, Surgut State Pedagogical University, Russia. 
Также следует помнить, что досуговая деятельность подчиняется принципу необходимости как с физической, так и социальной сторон.

Досуг - необходимая и неотъемлемая часть образа жизни каждого индивида, из чего следует, что досуговая деятельность направлена на реализацию интересов личности, связанных с самореализацией, саморазвитием, рекреацией, оздоровлением, удовольствием, общением и т.д. Но это не значит, что досуг стоит наравне с понятием «свобода», здесь стоит иметь в виду, что досуг подразумевает под собой наложение на индивида определенных обязанностей со стороны этической составляющей и моральных устоев, укорененных в обществе. При этом досуговая деятельность, подобно другим социальным явлениям, подвергается воздействию социальных сил.

Главным критерием оценки продуктивности и полезной составляющей досуга является наличие содержательного аспекта, под которым понимается причастность таких составляющих, как культура и этика. Если рассмотреть досуговую деятельность через призму культуры, то можно прийти к выводу, что культура чаще всего ассоциируется с позитивным развитием человека, высокой степенью его владения определенными нормами деятельности. Само же понятие «культура», в контексте вышесказанного, можно понимать как высокий уровень владения людьми нормами, стандартами деятельности, закрепленными в той или иной области социальной практики. В этом смысле говорят о культуре досуга, культуре общения, культуре речи, культуре потребления, корпоративной и профессиональной культуре и др. [1, с.12].

В процессе формирования культуры личности досуг должен быть сбалансированным по разным видам развлекательной, развивающей и рекреационной активности. Нельзя забывать, что досуг должен быть наполнен социально значимым смыслом. При этом досуговая активность реализуется как общественная необходимость.

На протяжении долгого времени в обществе складываются представления о желаемом характере досуга, о предпочтительных занятиях в свободное время, а также об определенных моральных требованиях, т.к. досуг обладает общественной значимостью. Это все говорит о том, что досуговая деятельность не может существовать без этики.

Если рассмотреть понятие «этика», то под данным определением понимается:

1. Философское учение о морали, ее развитии, принципах, нормах и роли в обществе;

2. Совокупность норм поведения (обычно применительно к какой-н. общественной группе).

В данном контексте под этикой досуга понимаются моральные принципы и духовные ценности, определяющие поведение человека в обществе.

С учетом указанных смысловых аспектов культурологическая и этическая трактовка досуговой деятельности также приобретает многознач- 
ность, т.е досуговая деятельность: развивается в рамках культуры конкретного сообщества; организуется на основе определенных этических норм и ценностей; предполагает использование досуга посредством свободного владения развитыми и общественно приемлемыми нормами поведения.

References:

[1] Аванесова, Г.А. Культурно-досуговая деятельность: Теория и практика организации: Учебное пособие для студентов вузов / Г.А. Аванесова. М.: Аспект Пресс, 2006. 236 c.

[2] Киселева, Т.Г. Социально-культурная деятельность: Учебник / Т. Киселева, Ю. Красильников. М.: МГУКИ, 2004. 539 с.

[3] Этика [Электронный ресурс]. - Режим доступа: http://ozhegov.info/slovar/?ex=Y\&q=\%D0\%AD\%D0\%A2\%D0\%98\%D0\%9A\%D0\% 90 (дата обращения: 26.12.2016) 